\title{
Restoring a perspective
}

\author{
Stephen Hancocks OBE \\ Editor-in-Chief
}

The BDJ Upfront section includes editorials, letters, news, book reviews and interviews. Please direct your correspondence to the News Editor,

Adrian O'Dowd at BDJNews@nature.com. Press releases or articles may be edited, and should include a colour photograph if possible.

W

e were fortunate as dental students to have Professor Robert Harkness as a physiology tutor. For us he possessed some of the classic traits of an academic eccentric, in the nicest possible way. I recall for example a tutorial in his delightfully chaotic office when the phone rang and, languidly unstacking books, moving jumpers and just managing to prevent a mudslide of folders, he lifted the receiver the moment the ringing stopped. 'Ah well, if it was important they would call back.'

Somewhat inexplicably to us he spent part of his summers in Greece counting ants marching in and out of their hills in various formations, locations and times of day. For him it was the fascination of observing, recording and analysing behaviour. Over time I have grown to respect that enthusiasm, admire the dedication and appreciate the knowledge so accumulated.

He has been in my mind recently because of the series we have been publishing in the journal by Professor Trevor Burke and Dr Steve Lucarotti with the overall title 'The ultimate guide to restoration longevity in England and Wales'. Not that for a moment am I likening the two subject areas of restorative dentistry and ants-nests other than to compare the value of real life data and skilful analysis. The series is based on a massive set of figures released relatively recently which consists of records of treatment of general dental services' adult patients in England and Wales between 1990 and 2006. Based on three million patients and over 25 million courses of treatment the data are derived from payment claims from general dental practitioners made to the Dental Practice Board, famously headquartered in Eastbourne, Sussex, UK for many years. As such it is arguably the largest available set of such information ever amassed and has provided the authors with not only a rich seam of knowledge to mine but concomitantly a huge task in trying to analyse and make sense of it.

This they have done with a remarkable clarity and we are delighted to be able to publish the series as a landmark in the analysis not only of the longevity and robustness of restorative dentistry but, most importantly, of restorations crafted and provided in real time, in real lives and in the real world. There probably is no better test of what works and what does not. The series makes for fascinating reading and although I appreciate that for a leisurely read it is not exactly Tolstoy, the cumulative effect of the analysed data is something of a War and Peace in terms of its value to us for application to patient care. We can apply what we have observed of actual behaviour from the of dental material science; a type of nirvana or pravda against which we might otherwise measure our performance. Arguably also the contrast between ivory tower academic research and what happens in actuality.

If anything, for me, this next layer of disclosure is of even more fascination because it reveals the true nature of our profession in that the work that we do is constantly tested, amended, flexed, moulded and shaped by a myriad of factors. These are interrogated by the analysis given in the papers; the type of materials used, the design of the restorations, the financial system under which they were placed, the demographics of the patients in whom they were placed including age and requirement to pay or not, the age and gender of the dentist and so forth. When

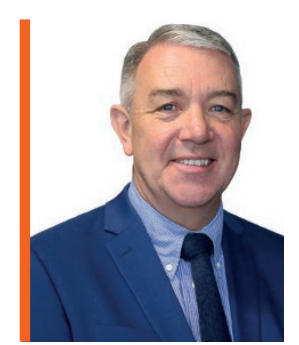

'We can apply what we have observed of actual behaviour from the past to our decision making in the future...' past to our decision making in the future and, as a recent letter to the Journal indicated (BDJ 2018; 225: 375) this has actually been happening and influencing clinical choices.

There are multiple layers to the papers which reflect the size of the data set and the route of analysis. On one level there are the actual lengths of time of retention and function of the restorations placed, sometimes surprising in themselves but given added power by the ability to track not only their inherent longevity but also that of the teeth so restored. On another level, and this is where my mind strayed to the ant analogy, the complexity of the decision-making process in everyday life is mapped on top of the otherwise apparently perceived purity being taught in the 'pure' sense how to create a class II cavity, for instance, almost none of these factors would be mentioned or considered. Yet in the hurly burly of general dental practice these form the maelstrom of considerations that we have to compute in making the clinical decisions that we do.

All of which serves to explain and emphasise on paper what we all know to be the case in daily practice that we are individuals who make decisions for the individuals we treat; almost certainly one of the main drivers that appealed to us in becoming part of the dental profession in the first place. A view which we might reasonably interpret as a restorative of a different nature.

DOI: 10.1038/sj.bdj.2018.933 